\title{
Cross-country learning from patents: an analysis of citations flows in innovation trajectories
}

\author{
Carlo Giglio $^{1}$ (D) $\cdot$ Roberto Sbragia $^{2} \cdot$ Roberto Musmanno $^{3} \cdot$ Roberto Palmieri $^{3}$
}

Received: 1 January 2021 / Accepted: 24 June 2021 / Published online: 10 July 2021

(c) The Author(s) 2021

\begin{abstract}
This study proposes a methodological approach to investigate cross-country creativity/ knowledge flows by analyzing patent citation networks, taking the aircraft, aviation and cosmonautics (AAC) industry as a case study. It aims at shedding some light on the following research questions: (a) how cross-country creative/learning flows can be investigated; (b) have countries of current patent owners benefited from patent acquisitions. In fact, despite the well-established economic interest for (analyzing and forecasting) innovation trajectories, this research area is still unexplored, thus, motivating the need for such study. Over 43,000,000 patents have been analyzed whereby: (a) owners have performed crosscountry patent acquisitions; (b) acquired patents (granted within 2005-2009) are cited by subsequent patents (2010-2015). Methodology and results are scalable to other industries and can be exploited by managers and policy makers to: (a) help firms forecasting innovation trajectories; (b) support governments in designing/implementing measures nurturing patented innovations in industries deemed relevant to national interest.
\end{abstract}

Keywords Knowledge flows · Creativity flows - Technology diffusion · Patent analysis · Patent citations · Aerospace industry

Carlo Giglio

carlo.giglio@unirc.it

Roberto Sbragia

rsbragia@usp.br

Roberto Musmanno

roberto.musmanno@unical.it

Roberto Palmieri

roberto.palmieri@unical.it

1 Department of Civil, Energy, Environmental and Material Engineering, Mediterranean University of Reggio Calabria, Via Graziella, Località Feo di Vito, Reggio Calabria, Italy

2 School of Economics, Business and Accounting, University of São Paulo, Avenida Professor Luciano Gualberto, 908, São Paulo, SP, Brazil

3 Department of Mechanical, Energy and Management Engineering, University of Calabria, Via Pietro Bucci, cubo 46/C, ponte carrabile, Rende, CS, Italy 
JEL codes O30 General · O31 Innovation and Invention: Processes and Incentives · O32 Management of Technological Innovation and R\&D · O33 Technological Change: Choices and Consequences · Diffusion Processes · O34 Intellectual Property and Intellectual Capital

\section{Introduction}

Patent citations and the corresponding networks have widely been (and still are) used to understand whether and how beneficial knowledge flows were in terms of both scope and intensity of knowledge diffusion (Breschi et al., 2005; Griliches, 1990; Hall et al., 2005; Harhoff et al., 1999; Lanjouw \& Schankerman, 2004; OECD, 1994; Trajtenberg, 1990), whilst creativity flows have not been considered at all in the extant literature on patent citations. Most of those studies refer to a (sometimes implicit) condition: Applicants of citing and cited patents are different. In other words, tracking patent citations flows has mainly been aimed at estimating knowledge diffusion. Nonetheless, to the best of our knowledge, few specific studies have focused on the knowledge diffusion properties characterizing specific technological fields-i.e. knowledge paths and decay-and procedural peculiarities of patent offices worldwide-i.e. patent office bias. Bacchiocchi and Montobbio, (2010) have shown that both aspects are significant, if taken separately, coherently with previous reference studies (Caballero \& Jaffe, 1993; Hall, Jaffe \& Trajtenberg, 2001). An even lesser quota of such studies deals with the combined effect of technological specificity and patent office bias. Since our study focuses on technological fields specifically relevant to the aircraft, aviation and cosmonautics (AAC) industry-i.e. class B64 based on both the International Patent Classification (IPC) and Cooperative Patent Classification (CPC) -, it ensures that procedural and technology classification issues do not affect our analysis, coherently with validated approaches in literature (Duguet \& MacGarvie, 2005; Jaffe et al., 2000).

A further area of analysis in literature is centred on the geographical and technological scope of patented innovations, which is dealt with in ground-breaking studies conducted in the last two decades (e.g. Jaffe, Trajtenberg and Henderson, 1993; Jaffe \& Trajtenberg, 1999; Maruseth \& Verspagen, 2002; Bottazzi \& Peri, 2003; Peri, 2005; Criscuolo \& Verspagen, 2008; Breschi \& Lissoni, 2009). In these works, it has been proved that inventors tend to cite other applicants of the same country, thus, neglecting possible more relevant cross-country citations. Self-citations are highly adopted as well, thus, increasing samecountry citations. Hence, cross-country citations between applicants of citing patents and inventors of previous cited patents are furtherly reduced: Same country-citations and selfcitations rely on and are affected by a country-specific technological environment. As such, this phenomenon may affect the openness and the overall development of the national technological field at hand and may play a key role in the business competitiveness at the national level. This remark puts the need for analyzing country-of-origin effect to the forefront of patent citation studies, since it may serve to the twofold objective of: (a) providing managers with a competition-relevant foresight tool to identify key conditions fostering creativity-/knowledge-based innovation processes; (b) supporting policy-makers to design and implement appropriate measures fostering technology advancements and industry's competitiveness at the national level.

This work is structured as follows: after the introduction, Sect. 2 provides a literature review on cross-country citations flows in patent citation networks and the motivation of 
the paper; in Sect. 3, data collection and methodological aspects are described; Sect. 4 includes results and discussions; Sect. 5 ends with conclusions.

\section{Literature review and motivation}

The existing literature dealing with cross-country learning from patents shows a twofold focus-i.e. macroeconomic and microeconomic (Bacchiocchi \& Montobbio, 2010; Griliches, 1990). The former includes the analysis of knowledge flows between applicants from different countries, emphasizing how the different nature, type, scope and intensity of knowledge diffusion affect the economic growth and industry's competitiveness at the country level (Chen \& Guan, 2016; Hu \& Jaffe, 2003; Malerba \& Montobbio, 2003; Malerba, Mancusi \& Montobbio, 2007; Maruseth \& Verspagen, 2002; OECD, 1997; Park et al., 2009; Shih \& Chang, 2009). Knowledge interactions at large include a wide range of other activities impacting on a country's macroeconomic perspective-e.g. joint industry collaborations, social interactions, public-private co-operations (OECD, 1997). Finally, all of them help achieving higher economies of scale by pooling and exploiting synergistically the assets of national innovation systems, and help steering the innovation and technical progress of countries towards worldwide technology frontiers (Chen \& Guan, 2016; Gomes-Casseres et al., 2006; Guan \& Chen, 2009; Hong, 2008; Inoue et al., 2010; Nakajima et al., 2010; OECD, 1997; Shin \& Park, 2007). For each industry, such frontiers are defined by a core group of innovating countries (Hu \& Jaffe, 2003), while peripheral ones benefit progressively from them through knowledge absorption. Hence, the technological potential (and corresponding advancements and trajectories) of macroeconomic agglomerates-e.g. countries, regions - could be ranked and improved through appropriate policies (Bekkers \& Martinelli, 2012; Chen \& Guan, 2010; David et al., 2011; Fleming et al., 2007; Mina et al., 2007; Stople, 2002; Verspagen, 2007).

Such differences in knowledge diffusion patterns among countries affect also firm-level dimensions like the (micro-)economic value of patented innovations and firms' competitiveness ( Chen \& Guan, 2016; Belderbos, 2001; Deng, 2008; Frietsch \& Grupp, 2006; Griliches, 1990; Ma et al., 2009; Storto, 2006; Verspagen, 2007). Again, most knowledge flows are enclosed within few core groups of innovating firms, which provide firms with a higher likelihood to increase the economic value of their patents. Likewise, patented innovations from firms in core innovating countries are 30-80\% more likely to be cited than others (Jaffe \& Trajtenberg, 1999). Finally, they represent a cluster of intra-industry cited and citing patents, which acts as a centre of gravity for the overall industry competitiveness flagship at the national level.

In conclusion, these results prove that macroeconomic and microeconomic dimensions should be combined together to ensure a deeper understanding of citations flows impacts on both the policy-making and firm levels.

Moreover, in our study we focus on patent acquisitions, neglecting on purpose other patent transfer or exchange methods and procedures (e.g. licensing agreements, transfer, co-operation, alliance, and mergers and acquisitions agreements). Patent acquisitions have been dealt with in previous studies (Ahuja \& Katila, 2001; Giglio, 2021; Kim \& Lee, 2019). Kim and Lee, (2019) highlight that there is a lack of empirical studies on patent acquisitions due to the complexity and contingency of contracts as well as to the difficulty of gathering comprehensive data on the subject. Such a gap in literature further justifies the need of our work to fill it in, and proves its novelty. Moreover, in their pillar work, 
Kim and Lee, (2019) prove also how patent acquisition activity is linked to the specificities related to the applicant and the technology at hand, with a clear impact on subsequent patenting activity. Ahuja and Katila, (2001) analyze patent acquisitions within acquisitions. They distinguish among non-technological, technological, and partly-technological acquisitions in order to investigate on their impact on the innovation output of acquiring firms. Caviggioli and Ughetto, (2013) analyze the main drivers of patent licensing and sales, and the impacts of marketplaces and brokers on patent transactions. Specific studies on the relationship among patent age and selling price have been conducted (Vimalnath et al., 2017), but they are still limited, too (Kim \& Lee, 2019). A higher, but still limited, quota of studies is focused on patent auctions (Caviggioli \& Ughetto, 2013; Fischer \& Leidinger, 2014; Odasso et al., 2015; Piirainen, Andersen \& Andersen, 2013; Sneed \& Johnson, 2009; Sreekumaran Nair et al., 2011; Vimalnath et al., 2017) and reassignments (Caviggioli et al., 2017; Drivas \& Economidou, 2015; Figueroa \& Serrano, 2013; Galasso et al., 2013; Serrano, 2010). In detail, only Drivas and Economidou, (2015) investigate on the geographic aspects related to knowledge flows, but they focus on cross-organizational patent acquisitions within the U.S. only. Hence, a twofold gap in literature is identified: the lack of investigation of cross-country knowledge flows; the creativity flows at large (Giglio, 2021). In all cases, Kim and Lee, (2019) conclude that the few empirical studies on patent transactions have a limited range of data and span over a variety of research interests, whilst Giglio (2021) highlights (amongst other) that future studies need to combine the analysis of knowledge and creativity flows at the cross-country level, in order to inform decision-making processes of both policy-makers and managers. Under a methodological perspective, Giglio, (2021) represents also the key work our methodology is built on, since it: Adopts and tests the same methodology on a different technology field; analyzes crosscountry knowledge and creativity flows based on patent acquisition processes; uses data extracted from the same data source (i.e. Bureau Van Dijk's - a Moody's Analytics Company), selecting only acquired patents with subsequent citing patents.

The reason for choosing only acquired patents as the subject of this study is fourfold. Firstly, as an industry-specific motivation, companies operating in highly competitive scenarios-like the AAC one-acquire mostly strategic patents which they aim at building on. Secondly, AAC companies are used to combine patent acquisition and talent recruitment: despite knowledge is inherent in people, the specific AAC-context is such that patent acquisitions can finally be considered as proxy for knowledge acquisitions. Hence, AAC firms could further develop the inherent knowledge and competitive advantages through the ownership and control of patent portfolios and their corresponding technological trajectories. Finally, patent acquisitions prove to what degree a firm is committed to shape the AAC industry and assume its technological leadership. Thirdly, our data sources made available only data on patent acquisitions. Fourthly, mixing data on patent acquisitions with data on other kinds of patent transfer or exchange methods and procedures would not be methodologically appropriate and would conduct to misleading results.

In addition, still no AAC-specific studies have been conducted so far, thus, motivating us to focus on this industry and to check whether previous results in literature apply also to this field or not (Caballero \& Jaffe, 1993; Jaffe, Trajtenberg and Henderson, 1993; Jaffe \& Trajtenberg, 1999; Jaffe \& Trajtenberg, 1999; Jaffe et al., 2000; Hall, Jaffe \& Trajtenberg, 2001; Maruseth \& Verspagen, 2002; Bottazzi \& Peri, 2003; Duguet \& MacGarvie, 2005; Peri, 2005; Criscuolo \& Verspagen, 2008; Breschi \& Lissoni, 2009; Bacchiocchi \& Montobbio, 2010). Finally, despite the national-level analysis has been addressed by several studies already mentioned in this section, only a minority quota has enlarged the perspective of analysis up to the international level (Shih \& Chang, 2009). Hence, this further 
proves that this paper covers an underexplored, but relevant area in the field of patent citation studies.

\section{Methodological approach and data collection}

\section{Sample and methodology}

The overall methodological approach and the corresponding steps are summarized below (Fig. 1) and discussed in detail in the rest of this section. As a premise, the data processed in this work have been extracted from the Bureau Van Dijk's - a Moody's Analytics Company - commercial database, that merges and harmonizes data from different patent databases globally. Therefore, preliminary methodological steps performed in other works - e.g. Kim and Lee's, (2019) one -, aimed at standardizing and cleansing applicants' names, deriving metrics from the raw data etc., are not needed, as BVD's database already provided ready-to-use data, as demonstrated in another recent work using BVD's data (Giglio, 2021).

The initial dataset counts 43,398,524 granted patents included in the European Patent Office's (EPO) database, which are labelled as relevant to the AAC industry. In the first step, such records include the following areas for the IPC and CPC:

- B64B-Lighter-Than-Air Aircraft;

- B64C-Aeroplanes; Helicopters;

- B64D-Equipment For Fitting In Or To Aircraft; Flying Suits; Parachutes; Arrangements Or Mounting Of Power Plants Or Propulsion Transmissions;

- B64F-Ground Or Aircraft-Carrier-Deck Installations;

- B64G-Cosmonautics; Vehicles Or Equipment Therefor.

In the second step, we have selected separately only those granted patents pertaining to this field according to either the IPC or CPC. The reason behind this narrowing approach is twofold. Firstly, the need of standardizing the selection methodology of those patents to be analyzed to minimize procedural and classification biases. Secondly,

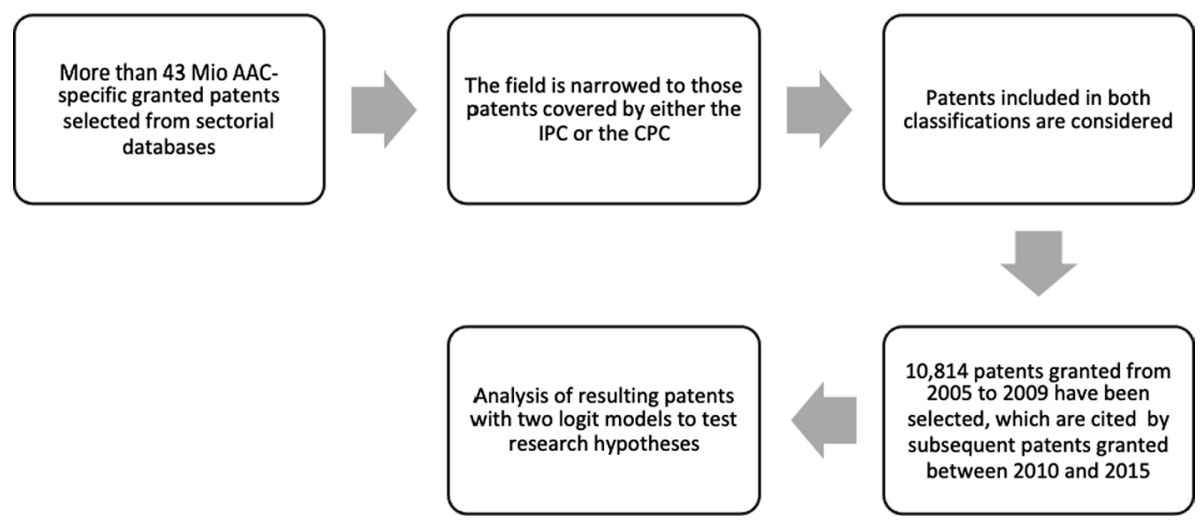

Fig. 1 Methodological approach and stages 
making the output of this pre-processing phase even more reliable by ensuring high homogeneity. As a result, 361,652 patents belong to the IPC and 283,646 to the CPC. In the third step, only those patents at the intersection of both IPC and CPC have been considered to further ensure their relevance to the AAC industry. This way, most of the methodological limitations (Bacchiocchi \& Montobbio, 2010) about procedural biases (different patent examination and classification processes) are overcome. In the fourth step, the resulting dataset has been limited to those 10,834 patents granted from January $1^{\text {st }}, 2005$, to December $31^{\text {st }}, 2009$, cited by subsequent patents granted between January $1^{\text {st }}, 2010$ and December $31^{\text {st }}, 2015$. Hence, the methodological approach relies on two consecutive periods for both cited patents and citing patents: they are sized up coherently with Li-Ying et al. (2013) to obtain a sufficiently large dataset for analyzing the country-of-origin effect and the corresponding knowledge flows. Among cited patents, only those acquired by new owners have been selected, using the same approach of a very recent work in literature (Giglio, 2021). In detail, acquired patents have been identified through BVD's data: specific columns report the existence of an acquisition process, providing also the IDs of different owners over time. Therefore, acquired patents are also easily differentiated by construction from non-acquired patents in this database. Finally, we also checked for the IDs of owners, assignees, and applicants in order to exclude potential relationships between different owners' IDs - e.g. between global groups and corresponding country affiliates. Citing patents have been selected over a six-year period (2010-2015) to ensure that their owners could exploit the knowledge acquired from inventors and show a "learning-by-acquisition" effect by building on previously acquired cited patents. Although, to the best of our knowledge, field literature does not provide a universally accepted time interval for learning-effect analyses based on patents, we rely on the 5-year elasticity of patenting for R\&D departments (Hausman \& Griliches, 1984), in agreement with Johnson, (2002), Ahuja and Katila, (2001), Hall, Jaffe and Trajtenberg, (1999; 1996). Moreover, Jaffe and Trajtenberg's analyses, (1996, 1999) on the US Patent and Trademark Office (USPTO) reveal a citation-lag distribution of about 5 years as well, especially for intra-industry citations like in this AAC-industry research study. In summary, extant literature supports the choice of two subsequent periods with similar length. No geographical filters as well as other attributes have been flagged to test the country-of-origin effect about both the existence of and the relevance to creative/knowledge flows. In this step, uncomplete or missing data have been deleted: only fully complete tuples are used in order to test research hypotheses. In the fifth and last step, data have been analyzed with two logit models to understand whether beneficial creativity and knowledge flows could be identified for owning firms-and, more broadly, for their headquarter countries, under a macroeconomic perspective. So, as an overall methodological remark, all data have been gathered from sectorial databases, thus, ensuring homogeneity and reliability.

In detail, the innovative algorithm has been designed based on the methodological approach described above. Under an operating perspective, the algorithmic steps from the first to the fourth have been implemented by means of Java computer-programming language ad well as NetBeans IDE 8.2. The fifth and last step has been executed by means of IBM® SPSS ${ }^{\circledR}$ Statistics 24, after having checked and deleted overlapping data. Some analyses have been made to make inferences about data and to understand whether the observed pattern is real or due to chance. The algorithm's steps are described in pseudo-code below: 


\section{Step 1.}

$\forall$ Patent $_{h} \in$ PatentSource, $h=1, \ldots, \mid$ PatentSource $\mid$

If (Patent ${ }_{i}$ class $\in$ AACIndustry) \{

Add Patent ${ }_{h}$ to AACIndustrySet;

\section{Step 2.}

$\forall$ Patent $_{i} \in$ AACIndustrySet $, i=1, \ldots, \mid$ AACIndustrySet $\mid\{$

Get Patent $_{i}$ class category from IPCClassSource

If Patent $_{i}$ class category $\in$ AACIndustrySet \{

If $(\text { Patent } \text { class category } \in I P C)_{\text {c }}$ \{

Add Patent $t_{i}$ to IPCSubset

\}

\}

Get Patent ${ }_{i}$ class category from CPCClassSource

If Patent $_{i}$ class category $\in$ AACIndustrySet \{

If $\left(\right.$ Patent $_{i}$ class category $\left.\left.\in C P C\right)\right\}$

Add Patent $t_{i}$ to CPCSubset

\}

\}

Step 3.

Create MatchingSubSet $\mid$ MatchingSubSet $=($ IPCSubSet $\cap$ CPCSubSet $)$

If MatchingSubSet $!=\{\varnothing\}\{$

Go to Next Step

Step 4.

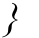

$\forall$ Patent $_{h} \in$ PatentSource, $h=1, \ldots, \mid$ PatentSource $\mid$

If (Patent $_{h}$ date $\geq 01-J a n-2010 \&$ Patent $_{h}$ date $\left.\leq 31-D e c-2015\right)\{$

Add Patent ${ }_{h}$ to SubsequentPatentSet;

\}

$\forall$ Patent $_{j} \in$ MatchingSubSet $, j=1, \ldots, \mid$ MatchingSubSet $\mid$

If (Patent $_{j}$ date $\geq 01-J a n-2005 \&$ Patent $_{j}$ date $\leq 31$-Dec-2009) \{

If $\exists$ Patent $_{k}$ SubsequentPatentSet $\mid$ Patent $_{k}$ is cited by Patent S $_{\{}$

Add Patent ${ }_{j}$ to the AnalysisSubSet

\}

\section{Step 5.}

Test research hypotheses on the AnalysisSubSet. 


\section{Variables and measures}

In line of the extant literature, we mainly support our analysis based on Giglio, (2021), Kessler and Bierly's, (2000), Verspagen's, (2007) and Li-Ying et al., (2013) works. In detail, patents mentioning prior arts in their applications prove that the latter were somehow useful to develop the citing patent. On the contrary, those new patents filed from the acquiring owners, which do not cite the patents previously acquired from abroad, show that such owners maintained relevant creativity levels compared to the knowledge domain of their portfolio of acquired patents. In fact, according to Giglio, (2021), prior innovations always provide some quotas of relevant knowledge, which (directly or indirectly) contribute to either the "learningby-acquisition" process or the creative one. This is coherent with Lai et al., (2021) findings on knowledge flows and patent connectivity, that may form a technology development path over time (see also Hummon and Dereian, (1989). In detail, when prior acquired knowledge is not utilized - i.e. it is not cited in new patents -, hence, creativity replaces it as the main innovation trigger (Giglio, 2021; Li-Ying et al., 2013; Verspagen, 2007). Most tellingly, when new patents are generated by an organization-which built on prior acquired patents from other organizations located in different countries -, a cross-country learning effect clearly took place (Kessler \& Bierly, 2000). If new patents are not based on prior arts, creative dynamics are activated and are more relevant than the knowledge-based ones, vice versa (Giglio, 2021).

In summary, we define our dependent variable as a binary cross-country learning variable, "DepVar" ( $0=$ no cross-country learning, $1=$ cross-country learning). In particular, we report the existence of a cross-country learning if the citing patent cites one or more prior acquired patents, whereby all current owners and all inventors come from different countries. No crosscountry learning refers to creativity, instead.

Our main independent variable is the number of cross-country patent acquisitions, "IndVar", that is the amount of patents acquired by owners based in countries different from the inventors' ones.

In addition, due to issues affecting patent citation studies-e.g. same country- and self-citations, technology- and patent office-specific aspects-discussed in Sects. 1 and 2, we define also some control variables, coherently with Li-Ying et al., (2013), for the analysis of knowledge flows, while we propose a variant of their model suitable for the analysis of creativity flows. In detail, we checked for technology- and firm-level as well as environmental variances. In Tables 1, 2, we show our control variables' levels, codes, names and brief descriptions for the analysis of knowledge and creativity flows, respectively. In Table 3, some descriptive statistics are reported.

Based on the binary dependent variable in our study, binary logistics models are appropriate. Finally, we adopt the logit model, as suggested by Greene, (2003) and Li-Ying et al., (2013). We conduct two logit tests: we refer to them as "Knowledge Flow" and "Creativity Flow" models, respectively.

\section{Results and discussion}

The statistical analysis has been conducted by means of IBM® SPSS $®$ Statistics 24. Before processing the data, the sample has been cleaned up by deleting overlapping observations. In Tables 4,5 we test correlations among independent variables to investigate about possible multicollinearity issues. 


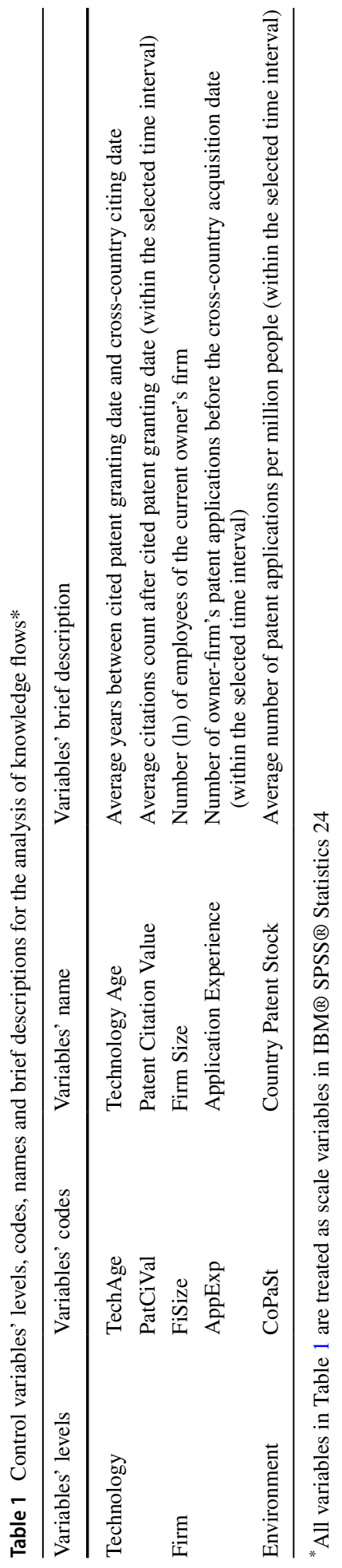




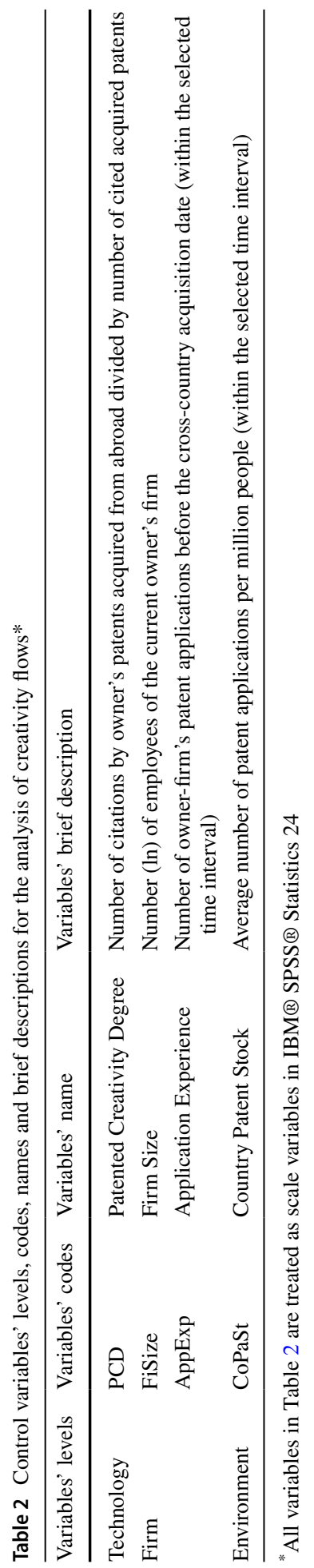


Table 3 Descriptive statistics: mean and std dev

\begin{tabular}{llllr}
\hline Variables' levels & Variables' codes & Variables' name & Mean & Std Dev \\
\hline Technology & TechAge & Technology Age & 0.632 & 1.523 \\
& PatCiVal & Patent Citation Value & 0.499 & 1.802 \\
Firm & FiSize & Firm Size & 7.421 & 1.190 \\
& AppExp & Application Experience & 39,026 & $59,453.290$ \\
Environment & CoPaSt & Country Patent Stock & 54.572 & 8.902 \\
Technology & PCD & Patented Creativity Degree & 18.992 & 15.531 \\
Firm & FiSize & Firm Size & 7.367 & 1.530 \\
& AppExp & Application Experience & 39,201 & $82,329.011$ \\
Environment & CoPaSt & Country Patent Stock & 23.532 & 9.201 \\
\hline
\end{tabular}

In Tables 4, 5 some variables show potential collinearity, as expected. As an overall remark, we find that correlation is high between the main independent variable measuring the number of cross-country patent acquisitions and the technology-level variables-Technology Age, Patent Citation Value, Patented Creativity Degree. In Table 5, the country-level analysis shows to be not significant, instead. This may suggest that, in the AAC industry, the time needed to develop new patents, the amount of citations and the degree of creativity tend to affect the attractiveness of "foreign patents" to be acquired from different countries. Likewise, in both Knowledge Flow and Creativity Flow models, the firm-level control variables show a significant correlation with each

Table 4 Correlation test for the Knowledge Flow model

\begin{tabular}{llllllll}
\hline \multirow{2}{*}{ IndVar } & IndVar & TechAge & PatCiVal & FiSize & AppExp & CoPaSt \\
& Pearson Correlation & 1 & $.627^{* *}$ & $.984^{* *}$ & .023 & -.089 & .042 \\
& Sig. (2-tailed) & & .000 & .000 & .801 & .334 & .647 \\
& $\mathrm{~N}$ & 120 & 120 & 120 & 120 & 120 & 120 \\
TechAge & Pearson Correlation & $.627^{* *}$ & 1 & $.747^{* *}$ & .045 & -.127 & .043 \\
& Sig. (2-tailed) & .000 & & .000 & .626 & .168 & .643 \\
& N & 120 & 120 & 120 & 120 & 120 & 120 \\
PatCiVal & Pearson Correlation & $.984^{* *}$ & $.747^{* *}$ & 1 & .029 & -.106 & .040 \\
& Sig. (2-tailed) & .000 & .000 & & .757 & .248 & .662 \\
& N & 120 & 120 & 120 & 120 & 120 & 120 \\
& Pearson Correlation & .023 & .045 & .029 & 1 & $.584^{* *}$ & $.282^{* *}$ \\
& Sig. (2-tailed) & .801 & .626 & .757 & & .000 & .002 \\
& N & 120 & 120 & 120 & 120 & 120 & 120 \\
AppExp & Pearson Correlation & -.089 & -.127 & -.106 & $.584^{* *}$ & 1 & $.331^{* *}$ \\
& Sig. (2-tailed) & .334 & .168 & .248 & .000 & & .000 \\
& N & 120 & 120 & 120 & 120 & 120 & 120 \\
& Pearson Correlation & .042 & .043 & .040 & $.282^{* *}$ & $.331^{* * *}$ & 1
\end{tabular}

${ }^{* *}$ Correlation is significant at the 0.01 level (2-tailed) 
Table 5 Correlation test for the Creativity Flow model

\begin{tabular}{llllllll}
\hline & & IndVar & PCD & Country & FiSize & AppExp & CoPaSt \\
\hline IndVar & Pearson Correlation & 1 & $.443^{* *}$ & -.114 & .107 & .084 & .137 \\
& Sig. (2-tailed) & & .001 & .421 & .451 & .555 & .334 \\
& $\mathrm{~N}$ & 52 & 52 & 52 & 52 & 52 & 52 \\
PCD & Pearson Correlation & $.443^{* *}$ & 1 & -.256 & .171 & .128 & .110 \\
& Sig. (2-tailed) & .001 & & .066 & .226 & .364 & .439 \\
& $\mathrm{~N}$ & 52 & 52 & 52 & 52 & 52 & 52 \\
Country & Pearson Correlation & -.114 & -.256 & 1 & .037 & .115 & .272 \\
& Sig. (2-tailed) & .421 & .066 & & .795 & .418 & .051 \\
& $\mathrm{~N}$ & 52 & 52 & 52 & 52 & 52 & 52 \\
FiSize & Pearson Correlation & .107 & .171 & .037 & 1 & $.286^{*}$ & .224 \\
& Sig. (2-tailed) & .451 & .226 & .795 & & .040 & .111 \\
& $\mathrm{~N}$ & 52 & 52 & 52 & 52 & 52 & 52 \\
AppExp & Pearson Correlation & .084 & .128 & .115 & $.286^{*}$ & 1 & $.421^{* *}$ \\
& Sig. (2-tailed) & .555 & .364 & .418 & .040 & & .002 \\
& $\mathrm{~N}$ & 52 & 52 & 52 & 52 & 52 & 52 \\
CoPaSt & Pearson Correlation & .137 & .110 & .272 & .224 & $.421^{* *}$ & 1 \\
& Sig. (2-tailed) & .334 & .439 & .051 & .111 &, 002 & \\
& $\mathrm{~N}$ & 52 & 52 & 52 & 52 & 52 & 52 \\
\hline
\end{tabular}

${ }^{* * *}$ Correlation is significant at the 0.01 level (2-tailed)

* Correlation is significant at the 0.05 level (2-tailed)

other. This may suggest that big-sized firms in the AAC industry tend to have a high number of patent applications, also before the cross-country patent acquisition that calls for inclination towards knowledge absorption. A further explanation is related to the fact that more employees in big firms tend to provide highly differentiated and/or highly specialized skills/knowledge. Moreover, they may have also more resources boosting technological innovation processes at their disposal. Therefore, this ensures those firms a higher capacity to upgrade existing knowledge and develop new patents. Moreover, significant cross-level correlation is found between firm- and environment-related control variables: it is lower than other correlation values in Table 4, whilst it is relatively high in Table 5. This result proves how firms are generally affected by the external environment: national innovation systems offering a breeding environment are associated with firms with high innovation potential and knowledge generation performances (LiYing et al., 2013). This is even more true in contexts where creativity-based innovation processes are relevant to the national industry and supported accordingly: we explain this way the relatively higher correlation value between firm- and environment-related control variables in Table 5. compared to Table 4. In summary, relationships between firm- and environment-level variables further prove that the microeconomic analysis should not be separated from the macroeconomic one: this underexplored combined approach is one of the motivations at the basis of our work, as stated in Sects. 1 and 2. Finally, as for the inter-level correlations, our analysis proves that no collinearity is detected between technology and firm levels, whilst the already discussed relationships between firm and environmental levels are entrenched. 
Table 6 "Knowledge Flow" logit model: classification table****

\begin{tabular}{lllll}
\hline Observed & \multicolumn{2}{l}{ Predicted } & \\
\cline { 3 - 5 } & & DepVar & $\begin{array}{l}\text { Percent- } \\
\text { age } \\
\text { Correct }\end{array}$ \\
\cline { 3 - 5 } & & .0000 & 1.0000 & \\
\hline DepVar & .0000 & 109 & 0 & 100.0 \\
& 1.0000 & 11 & 0 & .0 \\
Overall Percentage & & & 90.8 \\
\hline
\end{tabular}

${ }^{* * * *}$ Constant is included in the model. The cut value is .500 .

Table 7 "Knowledge Flow" logit model: test results****

\begin{tabular}{lllllll}
\hline & & Score & df & Sig & Log likelihood & Wald Chi $^{2}$ \\
\hline Variable Model 1 & IndVar & 47.531 & 1 & .000 & -80.233 & 29.536 \\
& TechAge & 120.020 & 1 & .000 & & \\
& PatCiVal & 80.357 & 1 & .000 & & \\
& AppExp & 2.808 & 1 & .020 & & 32.998 \\
& CoPaSt & .101 & 1 & .578 & & \\
Variables Model 2 & IndVar & 47.073 & 1 & .000 & -80.022 & \\
& TechAge & 110.956 & 1 & .000 & & \\
& PatCiVal & 68.446 & 1 & .000 & & \\
& FiSize & .186 & 1 & .666 & & \\
& AppExp & 2.274 & 1 & .132 & & \\
& CoPaSt & .053 & 1 & .817 & & \\
\hline
\end{tabular}

${ }^{* * * *}$ Significance threshold is $5 \%$

In Tables 6, 7, 8, 9 the results of the two logit models are shown. In Tables 6, 8, the analyses of knowledge and creativity flows prove to be highly reliable, since their overall percentages of predictability are high.

First, in Tables 6, 7, 8, 9 we find that our main independent variable-i.e. the number of cross-country patent acquisitions, "IndVar", whereas owners of prior acquired patents are headquartered in countries which differ from the inventors' ones.- - has a positive and significant effect on the cross-country learning variable as well as on the creative cross-country effect, while no firm- and environmental-level variables have relevant impacts. Results suggest that in the AAC industry the higher the number of cross-country patent acquisition, the higher the likelihood that the current owner-firm files new patents by citing the acquired technology. Also, the higher the number of cross-country patent acquisition, the higher the likelihood of being creative in the development of new patents (and corresponding products). Hence, we confirm the "learning-by-acquisition" effect that is those firms acquiring AAC-related foreign patents learn from them, develop new knowledge and file new technology in their home countries. We confirm also the "creating-by-acquisition" effect that is those firms acquiring AAC-related foreign patents are still able to maintain a relevant creativity and to generate innovations not based on those acquired patents. Also, we find no country having a more significant creative ability than other competitor-countries-except 
Table 8 "Creativity Flow" logit model: classification table*****

\begin{tabular}{|c|c|c|c|c|}
\hline \multirow[t]{3}{*}{ Observed } & & \multicolumn{3}{|c|}{ Predicted } \\
\hline & & \multicolumn{2}{|c|}{ DepVar } & \multirow{2}{*}{$\begin{array}{l}\text { Percent- } \\
\text { age } \\
\text { Correct }\end{array}$} \\
\hline & & ,0000 & 1,0000 & \\
\hline \multirow[t]{2}{*}{ DepVar } & ,0000 & 43 & 0 & 100,0 \\
\hline & 1,0000 & 9 & 0 & ,0 \\
\hline \multicolumn{4}{|c|}{ Overall Percentage } & 82,7 \\
\hline
\end{tabular}

***** Constant is included in the model. The cut value is .500

for the U.S.A. and Brazil. Therefore, managers should consider that firms operating in the AAC industry benefit from being located in the U.S.A. and Brazil as the corresponding environment-level conditions favour them when it comes to develop more creative, radical innovations compared to their competitors located in the remaining countries analysed. On the other hand, policy makers from other countries should also consider that those conditions implemented in the U.S.A. and Brazil represent a benchmark. Such results have a twofold relevance that is a microeconomic and a macroeconomic one. In fact, firms innovating because of a cross-country patent acquisition not only increase their own innovation potential, performance and competitiveness, but also increase them at the national level, coherently with literature discussed in Sect. 2 (Chen \& Guan, 2016; Hu \& Jaffe, 2003; Malerba \& Montobbio, 2003; Malerba, Mancusi \& Montobbio, 2007; Maruseth \& Verspagen, 2002; OECD, 1997; Park et al., 2009; Shih \& Chang, 2009; Shin \& Park, 2007). Hence, policy makers may assess a country's technological relevance to the AAC industry and its competitiveness worldwide as well as understand and anticipate technology development trajectories by means of strategic plans and operating tools, as suggested by previous studies discussed in Sect. 2 (Bekkers \& Martinelli, 2012; Chen \& Guan, 2010; David et al., 2011; Fleming et al., 2007; Mina et al., 2007; Stople, 2002; Verspagen, 2007).

Likewise, the technology-level control variables prove to be positively significant in terms of cross-country learning from patents in the AAC industry. On the contrary, firmand environment-level variables are not significant. These results seem to partly conflict with previous studies on cross-country learning from prior arts by Li-Ying et al., (2013). However, this is only apparently contradictory, since previous studies focused on the electronic sector, thus, confirming that the technology-specific diffusion is a relevant issue when dealing with knowledge flows from patent citation studies. Significance of Technology Age and Patent Citation Value may suggest that in the AAC industry both the time needed to develop new patents and the amount of citations tend to affect the attractiveness of "foreign patents" to be acquired from different countries. In brief, the "learning-byacquisition" effect is fostered by two aspects: (a) a short time needed to acquire and learn from a foreign technology as well as to develop new patents citing the former one; (b) a high number of citations achieved by the patent to be acquired from abroad. Those aspects also show a high correlation with our main independent variable in Table 4, therefore, we find direct evidence that Technology Age and Patent Citation Value affect significantly also cross-country patent acquisitions and, in turn, the latter has an effective impact on crosscountry learning. 
Table 9 "Creativity Flow" logit model: test results******

\begin{tabular}{|c|c|c|c|c|c|c|}
\hline & & Score & $\mathrm{df}$ & Sig & Log likelihood & Wald $\mathrm{Chi}^{2}$ \\
\hline \multirow[t]{21}{*}{ Variables Model 1} & IndVar & 15.551 & 1 & .000 & \multirow[t]{21}{*}{-92.553} & \multirow[t]{21}{*}{22.883} \\
\hline & PCD & 34.321 & 1 & .000 & & \\
\hline & Country & 22.899 & 16 & .052 & & \\
\hline & Country(1) USA & 12.790 & 1 & .000 & & \\
\hline & Country(2) The Netherlands & .308 & 1 & .582 & & \\
\hline & Country(3) Great Britain & 2.889 & 1 & .160 & & \\
\hline & Country(4) Israel & .353 & 1 & .582 & & \\
\hline & Country(5) France & 1.820 & 1 & .181 & & \\
\hline & Country(6) Switzerland & 1.201 & 1 & .201 & & \\
\hline & Country(7) Brazil & 5.778 & 1 & .003 & & \\
\hline & Country(8) Hong Kong SAR & .308 & 1 & .582 & & \\
\hline & Country(9) Luxembourg & .308 & 1 & .582 & & \\
\hline & Country(10) Germany & .532 & 1 & .390 & & \\
\hline & Country(11) Singapore & .308 & 1 & .582 & & \\
\hline & Country(12) Multiple countries & .308 & 1 & .582 & & \\
\hline & Country(13) Japan & .308 & 1 & .582 & & \\
\hline & Country(14) Finland & .703 & 1 & .388 & & \\
\hline & Country(15) Canada & .308 & 1 & .582 & & \\
\hline & Country(16) Ireland & .308 & 1 & .582 & & \\
\hline & AppExp & 1.993 & 1 & .281 & & \\
\hline & CoPaSt & 1,882 & 1 & .102 & & \\
\hline \multirow[t]{22}{*}{ Variables Model 2} & IndVar & 14,946 & 1 &, 000 & \multirow[t]{22}{*}{-90.331} & \multirow[t]{22}{*}{26.922} \\
\hline & PCD & 32,380 & 1 & ,000 & & \\
\hline & Country & 20,558 & 16 & , 196 & & \\
\hline & Country(1) USA & 11,650 & 1 & ,001 & & \\
\hline & Country(2) The Netherlands &, 213 & 1 & ,644 & & \\
\hline & Country(3) Great Britain & 1,979 & 1 & , 160 & & \\
\hline & Country(4) Israel & ,213 & 1 & ,644 & & \\
\hline & Country(5) France & 1,420 & 1 & ,233 & & \\
\hline & Country(6) Switzerland & ,907 & 1 &, 341 & & \\
\hline & Country(7) Brazil & 4,871 & 1 & ,027 & & \\
\hline & Country(8) Hong Kong SAR & ,213 & 1 & ,644 & & \\
\hline & Country(9) Luxembourg & ,213 & 1 & ,644 & & \\
\hline & Country(10) Germany & ,391 & 1 &, 532 & & \\
\hline & Country(11) Singapore & ,213 & 1 & ,644 & & \\
\hline & Country(12) Multiple countries & ,213 & 1 & 644 & & \\
\hline & Country(13) Japan &, 213 & 1 & ,644 & & \\
\hline & Country(14) Finland & ,435 & 1 &, 509 & & \\
\hline & Country(15) Canada &, 213 & 1 & ,644 & & \\
\hline & Country(16) Ireland &, 213 & 1 & ,644 & & \\
\hline & FiSize &, 556 & 1 &, 456 & & \\
\hline & AppExp & 1,003 & 1 &, 317 & & \\
\hline & CoPaSt & 1,419 & 1 &, 234 & & \\
\hline
\end{tabular}

******* Significance threshold is $5 \%$ 


\section{Conclusions}

This work claims a threefold originality contribution. Firstly, it proposes a relevant enquiry focusing on the "learning-by-acquisition" effect from patents in the AAC industry, which is an underexplored area of research deserving more room in patent citation studies, as discussed in Sects. 1 and 2. In fact, existing studies on knowledge flows through patent citations analysis have mainly been geared to assess to what extent knowledge diffusion at large was beneficial in terms of knowledge spillovers and new patent applications (; Harhoff et al., 1999; Breschi et al., 2005;; Griliches, 1990; Hall et al., 2005; Lanjouw \& Schankerman, 2004; OECD, 1994; Trajtenberg, 1990). Nonetheless, most of those efforts have neglected technology- or industry-specific knowledge diffusion issues. Moreover, we further deepen the industry-specific competition dynamics: firms not only tend to hire talents, but also acquire those patents enabling them to master entire technological trajectories and to shape the whole industry scenario. Hence, our study on "learning-by-acquisition" helps understanding if and to what degree a firm is committed to further develop and shape the industry it is operating in and the corresponding technological trajectory.

Secondly, this study adopts a new, complementary perspective. Since extant literature has neglected the spillover properties characterizing some specific technological fields, this work puts the analysis of industry-specific diffusion properties to the forefront. Last, but not least, Griliches, (1990) and Bacchiocchi and Montobbio, (2010) highlight that studies on knowledge and creativity flows and patent citations have a two-pronged significance that is macroeconomic and microeconomic one. Nonetheless, such a twofold aspect is still under-researched: existing literature neglects their conjoint analysis, by keeping on taking them separately (Bekkers \& Martinelli, 2012; Belderbos, 2001; Chen \& Guan, 2010, 2016; David et al., 2011; Deng, 2008; Fleming et al., 2007; Frietsch \& Grupp, 2006; Griliches, 1990; Hu \& Jaffe, 2003; Ma et al., 2009; Mina et al., 2007; OECD, 1997; Shin \& Park, 2007; Stople, 2002; Storto, 2006; Verspagen, 2007). Both these views are adopted in our study to show how beneficial is the combined understanding of knowledge diffusion and creative cross-country dynamics (and their practical implications) at the national and firm levels. Hence, this work opens a new window on creative/knowledge flows and their implications through patent citation studies.

Thirdly, under the methodological perspective, our approach overcomes the limitations reported as patent office bias by narrowing our sample to AAC-relevant patents included in both standardized classifications (IPC and CPC), avoiding procedural and categorization issues which may hinder our analysis. In summary, our methodology relies on a validated approach (Duguet \& MacGarvie, 2005; Jaffe et al., 2000) and is further strengthened by the reliability of the overall percentage of predictability in Tables 6,8. In addition, we define and test a creativity measure based on patent citations: it is the first work in literature proposing and coherently integrating it within the consolidated model proposed by Li-Ying et al., (2013).

As for the results, we prove that current owners operating cross-country patent acquisitions are able to internalize inventors' knowledge, to file subsequent patents in the AAC industry and to maintain their own creativity levels (especially in the U.S.A. and Brazil). This further proves the two-pronged advantage of cross-country learning, since firms increase their innovation potential and their business competitiveness, while countries strengthen their national innovation systems and foster their economic growth, coherently with the extant literature (Chen \& Guan, 2016; Hu \& Jaffe, 2003; Malerba \& Montobbio, 2003; Malerba, Mancusi \& Montobbio, 2007; Maruseth \& 
Verspagen, 2002; OECD, 1997; Park et al., 2009; Shih \& Chang, 2009; Shin \& Park, 2007). These results may have significant implications for policy makers, which may develop strategic plans and operating tools nurturing effectively the AAC industry (Bekkers \& Martinelli, 2012; Chen \& Guan, 2010; David et al., 2011; Fleming et al., 2007; Mina et al., 2007; Stople, 2002; Verspagen, 2007). In particular, policy makers willing to support the national ACC industry should encourage firms to acquire patents from abroad-e.g. with incentives, reduced taxation — and to integrate them into their organizational knowledge bases in order to develop new patents or stimulate their creativity. As for firm-level implications, managers should select foreign patented technology to be acquired by analyzing both technology age and citations obtained in order to increase the likelihood of benefitting from the "learning-by-acquisition" or creative cross-country effects. In detail, those patents endowed with the highest innovation potential are associated with a short time needed to internalize and exploit the acquired knowledge in new technological solutions, which may also be creative - i.e. not linked to the previous ones. Those patents that managers should acquire from abroad should also have a strong attractiveness in terms of high patent citation levels.

Moreover, we discuss limitations. Firstly, despite proving "learning-by-acquisition" and creative cross-country effects, we lack detailed data to clarify to what extent owner-firms have learned from prior acquired patents or have been creatively stimulated. Secondly, we lack the whole picture about why owner-firms benefit from foreign patent acquisition: Despite identifying some aspects (technology age, patent citations, creativity) to choose the technology to be acquired, we neglect others like individual creativity. Thirdly, we miss possible moderating/mediating roles of other factors, which may pave the way for future research efforts on knowledge and creativity flows, patent citations, "learning-by-acquisition" and creative cross-country effects.

Finally, we address future scope of research. Firstly, this work should be complemented by means of conducting a firm-level study on how different firms acquire AAC-related foreign patents. Secondly, future studies should also address the scenario of learning-byacquiring or creative effect, where a same firm has cited patents issued in different countries through its extensions.

Authors' contribution Conceptualization, CG; methodology CG; software, CG, RS, RM, and RP; validation, CG, RS, RM, and RP; formal analysis, CG; investigation, CG, RS, RM, and RP; resources, CG, RS, RM, and RP; data curation, CG, RS, RM, and RP; writing —original draft preparation, CG; writing - review and editing, CG, RS, RM, and RP; visualization, CG; supervision, CG; project administration, CG; funding acquisition, CG All authors have read and agreed to the published.version of the manuscript.

Funding Open access funding provided by Università degli Studi Mediterranea di Reggio Calabria within the CRUI-CARE Agreement. This research did not receive any specific grant from funding agencies in the public, commercial, or not-for-profit sectors.

Availability of data and material Proprietary data.

\section{Declarations}

Conflicts of interest The authors declare that they do not have any conflict of interest.

Open Access This article is licensed under a Creative Commons Attribution 4.0 International License, which permits use, sharing, adaptation, distribution and reproduction in any medium or format, as long as you give appropriate credit to the original author(s) and the source, provide a link to the Creative Commons licence, and indicate if changes were made. The images or other third party material in this article are included in the article's Creative Commons licence, unless indicated otherwise in a credit line to the 
material. If material is not included in the article's Creative Commons licence and your intended use is not permitted by statutory regulation or exceeds the permitted use, you will need to obtain permission directly from the copyright holder. To view a copy of this licence, visit http://creativecommons.org/licenses/by/4.0/.

\section{References}

Ahuja, G., \& Katila, R. (2001). Technological acquisitions and the innovation performance of acquiring firms: A longitudinal study. Strategic Management Journal, 22(3), 197-220.

Bacchiocchi, E., \& Montobbio, F. (2010). International knowledge diffusion and home-bias effect: Do USPTO and EPO patent citations tell the same story? Scand. J. of Economics, 112(3), 441-470.

Bekkers, R., \& Martinelli, A. (2012). Knowledge positions in high-tech markets: Trajectories, standards, strategies and true innovators. Technological Forecasting \& Social Change, 79, 1192-1216.

Belderbos, R. (2001). Overseas innovation by Japanese firms: An analysis of patent and subsidiary data. Research Policy, 20, 313-332.

Bottazzi, L., \& Peri, G. (2003). Innovation and spillovers in regions: Evidence from European patent data. European Economic Review, 47, 687-710.

Breschi, S., \& Lissoni, F. (2009). Mobility of skilled workers and co-invention networks: An anatomy of localized knowledge flows. Journal of Economic Geography, 9, 439-468.

Breschi, S., Lissoni, F., \& Montobbio, F. (2005). The geography of knowledge spillovers: conceptual issues and measurement problems. In S. Breschi \& F. Malerba (Eds.), Clusters networks and innovation. Oxford: Oxford University Press.

Caballero, J. R., \& Jaffe, A. B. (1993). How High Are the Giants' Shoulders: An Empirical Assessment of Knowledge and Creative Destruction in a Model of Economic Growth. In O. Blanchard \& S. Fisher (Eds.), National Bureau of Economic Research Macroeconomics Annual. Cambridge: MIT Press.

Caviggioli, F., \& Ughetto, E. (2013). The drivers of patent transactions: Corporate views on the market for patents. R\&D Manag., 43, 318-332.

Caviggioli, F., De Marco, A., Scellato, G., \& Ughetto, E. (2017). Corporate strategies for technology acquisition: Evidence from patent transactions. Management Decision, 55, 1163-1181.

Chen, Z. F., \& Guan, J. C. (2010). The impact of small world on innovation: An empirical study of 16 countries. Journal of Informetrics, 4, 97-106.

Chen, Z., \& Guan, J. (2016). The core-peripheral structure of international knowledge flows: Evidence from patent citation data. $R \& D$ Management, 46(1), 62-79.

Criscuolo, P., \& Verspagen, B. (2008). Does it matter where patent citations come from? inventor vs. examiner citations in european patents. Research Policy, 37, 1892-1908.

David, B.-T., Fernando, J.-S., \& Itziar, C.-M. (2011). Mapping the importance of the real world: The validity of connectivity analysis of patent citations networks. Research Policy, 40, 473-486.

Deng, Y. (2008). The value of knowledge spillovers in the U.S. semiconductor industry. International Journal of Industrial Organization, 26, 1044-1058.

Drivas, K., \& Economidou, C. (2015). Is geographic nearness important for trading ideas? Evidence from the US. The Journal of Technology Transfer, 40, 629-662.

Duguet, E., \& MacGarvie, M. (2005). How well do patent citations measure flows of technology? evidence from french innovation surveys. Economics of Innovation and New Technology, 14, 375-393.

Figueroa, N. and Serrano, C. (2013). Patent trading flows of small and large firms. Cambridge, MA.

Fischer, T., \& Leidinger, J. (2014). Testing patent value indicators on directly observed patent value - an empirical analysis of ocean tomo patent auctions. Research Policy, 43, 519-529.

Fleming, L., King, C., \& Juda, A. I. (2007). Small worlds and regional innovation. Organization Science, 18, 938-954.

Frietsch, R., \& Grupp, H. (2006). There is a new man in town: The paradigm shift in optical technology. Technovation, 26, 463-472.

Galasso, A., Schankerman, M., \& Serrano, C. J. (2013). Trading and enforcing patent rights. The Rand Journal of Economics, 44, 275-312.

Giglio, C. (2021). Cross-country creativity and knowledge flows of patent acquisitions: Drivers and implications for managers and policy-makers". Journal of Engineering and Technology Management, 59, 101617.

Gomes-Casseres, B., Hagedoorn, J., \& Jaffe, A. B. (2006). Do alliance promote knowledge flows? Journal of Financial Economics, 80, 5-33.

Greene, W. (2003). Econometric analysis (5th ed.). Pretice-Hall. 
Griliches, Z. (1990). Patent statistics as economic indicators: A survey. Journal of Economic Literature, 28, 1661-1707.

Guan, J. C., \& Chen, Z. F. (2009). The technological system of Chinese manufacturing industry: A sectorial approach. China Economic Review, 20, 767-776.

Hall, B. H., Jaffe, A. B. and Trajtenberg, M. (1999). Market value and patent citations. Paper presented at the NBER working paper, Paris.

Hall, B. H., Jaffe, A. B., and Trajtenberg, M. (2001). The NBER patent citation data file: lessons, insights and methodological tools. NBER Working Paper, 8498.

Hall, B. H., Jaffe, A. B., \& Trajtenberg, M. (2005). Market value and patent citations. Rand Journal of Economics, 36, 16-38.

Harhoff, D., Narin, F., Scherer, F. M., \& Vopel, K. (1999). Citation frequency and the value of patented inventions. Review of Economics and Statistics, 81, 511-515.

Hausman, J. A., \& Griliches, Z. (1984). Econometric models for count data with an application to the patents-R\&D relationship. Economic and Political Weekly, 27, 909-938.

Hong, W. (2008). Decline of the center: The decentralizing process of knowledge transfer of Chinese universities from 1985-2004. Research Policy, 37, 580-595.

Hu, A. G. Z., \& Jaffe, A. B. (2003). Patent citations and international knowledge flow: The cases of Korea and Taiwan. International Journal of Industrial Organization, 21, 849-880.

Hummon, N. P., \& Dereian, P. (1989). Connectivity in a citation network: The development of DNA theory. Social Networks, 11(1), 39-63.

Inoue, H., Souma, W., \& Tamada, S. (2010). Analysis of cooperative research and development networks on japanese patents. Journal of Informetrics, 4, 89-96.

Jaffe, A. B., Trajtenberg, M. and Henderson, R. (1993). Geographic Localization of Knowledge Spillovers as Evidenced by Patent Citations. Quarterly Journal of Economics, 108, 577-598.

Jaffe, A. B., \& Trajtenberg, M. (1996). Flow of knowledge from universities and federal laboratories: Modelling the flow of patent citations over time and across institutional and geographic boundaries. Proceedings of the National Academy of Sciences, 93, 12671-12677.

Jaffe, A. B., \& Trajtenberg, M. (1999). International knowledge flows: Evidence from patent citations. Economics of innovation and new technology 8, 105-136.

Jaffe, A. B., Trajtenberg, M., \& Fogarty, M. S. (2000). Knowledge spillovers and patent citations: Evidence from a survey of inventors. American Economic Review, 90, 215-218.

Johnson, D. K. N. (2002). 'Learning-by-licensing': R\&D and technology licensing in brazilian invention. Economics of Innovation \& New Technology, 11(3), 163-177.

Kessler, E. H., \& Bierly, P. E. (2000). Internal vs external learning in new product development: Effects on speed, costs and competitive advantage. R\&D Management, 30(3), 213-224.

Kim, S. Y., \& Lee, H. J. (2019). The effect of patent acquisition on subsequent patenting activity. World Patent Information, 59, 101933.

Lai, K.-K., Chen, H.-C., Chang, Y.-H., Kumar, V., \& Bhatt, P. C. (2021). A structured MPA approach to explore technological core competence, knowledge flow, and technology development through social network patentometrics. Journal of Knowledge Management, 25(2), 402-432.

Lanjouw, J. O., \& Schankerman, M. (2004). Patent quality and research productivity: Measuring innovation with multiple indicators. Economic Journal, 114, 441-465.

Li-Ying, J., Wang, Y., Salomo, S., \& Vanhaverbeke, W. (2013). Have Chinese firms learned from their prior technology in-licensing? An analysis based on patent citations. Scientometrics, 95, 183-195.

Ma, Z. Z., Lee, Y., \& Chen, C. (2009). Booming or emerging? China's technological capability and international collaboration in patent activities. Technological Forecasting \& Social Change, 76, 787-796.

Malerba, F., \& Montobbio, F. (2003). Exploring factors affecting international technological specialization: The role of knowledge flows and the structure of innovative activity. Journal of Evolutionary Economics, 13, 411-434.

Malerba, F., Mancusi, M. and Montobbio, F. (2007). Innovation, international R\&D spillovers and the sectoral heterogeneity of knowledge flows, CESPRI Working Paper no. 206.

Maruseth, P. B., \& Verspagen, B. (2002). Knowledge spillovers in europe: a patent citations analysis. Scandinavian Journal of Economics, 104, 531-545.

Mina, A., Ramlogan, R., Tampubolon, G., \& Metcalfe, J. S. (2007). Mapping evolutionary trajectories: Applications to the growth and transformation of medical knowledge. Research Policy, 36, 789-806.

Nakajima, R., Tamura, R., \& Hanaki, N. (2010). The effect of collaboration network on inventors' job match, productivity and tenure. Labour Economics, 17, 723-734.

Odasso, C., Scellato, G., \& Ughetto, E. (2015). Selling patents at auction: An empirical analysis of patent value. Industrial and Corporate Change, 24, 417-438. 
OECD (1994). Using patent data as science and technology indicators-Patent manual, OECD, Paris.

OECD (1997). National innovation systems. OECD Publications, Paris 9-10.

Park, J., Lee, H., \& Park, Y. (2009). Disembodied knowledge flows among industrial clusters: A patent analysis of the Korean manufacturing sector. Technology in Society, 31, 73-84.

Peri, G. (2005). Determinants of Knowledge Flows and Their Effect on Innovation. Review of Economics and Statistics, 87, 308-322.

Piirainen, K.a., Andersen, A.D. and Andersen, P.D. (2013). Foresight for Sectoral Development: Sectoral Development as a 'Third Mission' Activity at the Technical University of Denmark, In Paper presented at: International Foresight Academy-Seminar, 1-27

Serrano, C. J. (2010). The dynamics of the transfer and renewal of patents. The Rand Journal of Economics, $41,686-708$.

Shih, H. Y., \& Chang, T. L. S. (2009). International diffusion of embodied and disembodied technology: A network analysis approach. Technology Forecasting \& Social Change, 76, 821-834.

Shin, J., \& Park, Y. (2007). Building the national ICT frontier: The case of Korea. Information Economics and Policy, 19, 249-277.

Sneed, K. A., \& Johnson, D. K. N. (2009). Selling ideas: The determinants of patent value in an auction environment. $R \& D$ Manag., 39, 87-94.

Sreekumaran Nair, S., Mathew, M., \& Nag, D. (2011). Dynamics between patent latent variables and patent price. Technovation, 31, 648-654.

Stople, M. (2002). Determinants of knowledge diffusion as evidenced in patent data: The case of liquid crystal display technology. Research Policy, 31, 1181-1198.

Storto, C. (2006). Amethod based on patent analysis for the investigation of technological innovation strategies: The European medical prostheses industry. Technovation, 26, 932-942.

Trajtenberg, M. (1990). A penny for your quotes: Patent Citations and the value of innovations. Rand Journal of Economics, 21, 172-187.

Verspagen, B. (2007). Mapping technological trajectories as patent citation networks: A study on the history of fuel cell research. Advances in Complex Systems, 10, 93-115.

Vimalnath, P., Gurtoo, A., \& Mathew, M. (2017). The relationship between patent age and selling price across bundling strategies for United States patents, predominately for computer and communication technology. World Patent Information World, 48, 1-11. 